\title{
DE GESCHIEDENIS DER LUTHERSCHE GEMEENTE IN BERBICE
}

\section{I}

DOOR

\section{B. DE GAAY FORTMAN}

In $\mathrm{T} \mathrm{i} \mathrm{m} \mathrm{e} \mathrm{h} \mathrm{r} \mathrm{i,} \mathrm{the} \mathrm{journal} \mathrm{of} \mathrm{the} \mathrm{royal} \mathrm{agricultural} \mathrm{and} \mathrm{com-}$ mercial society of British Guiana van 1918 heeft Fred May een opstel geschreven, ,"The Lutherans of Berbice”. De schrijver was „colonial treasurer", en in drie en een halve bladzijde bepaalt hij zich nagenoeg geheel tot de geschiedenis der stoffelijke aangelegenheden dezer Luthersche gemeente, waarin hij hier en daar een greep doet. De toenmalige predikant dezer kerk, rev. Ralph J. White, heeft een jaar later in hetzelfde tijdschrift deze gegevens aangevuld met wat hij noemt de geschiedenis zijner gemeente, zooals de Lutheranen zelf die zien. Ook dit opstel is allerminst volledig. Waarschijnlijk zijn hiermee de in de kolonie aanwezige gegevens uitgeput.

De oudere geschiedschrijvers als mr. J. J. Hartsinck, Beschrijving van Guiana, of de Wilde kust in Zuid-America I, 1770, en P. M. Netscher, Geschiedenis van de koloniën Essequebo, Demerary en Berbice van de vestiging der Nederlanders aldaar tot op onzen tijd, 1888 , die de in Nederland aanwezige archieven geraadpleegd hebben, noemen de Luthersche gemeente in Berbice eenige malen terloops, zooals ook dr. L. Knappert doet in het $\mathrm{N}$ e de rlandsch archief voor kerkgeschiedenis (Mei 1930), waarin hij ,Eene bladzijde uit de kerkgeschiedenis van Essequebo, Berbice en Demerary" geschreven heeft.

Het is niet onwaarschijnlijk, dat met deze gegevens zoowel het kerkelijk archief in Berbice als de openbare archieven ginds en hier zijn uitgeput, en het mag een gelukkige omstandigheid genoemd worden, dat de Evangelisch Luthersche gemeente te Amsterdam in haar archief heeft bewaard niet alleen de notulen van haar consistoriale vergaderingen, waarin heel wat over de ge- 
meente in Berbice te vinden is, en de van daar ontvangen brieven maar ook de haar getrouwelijk toegezonden notulen van den kerkeraad in Berbice. De brieven loopen van 1743 tot 1846, dus lang over het tijdstip, waarop Berbice ophield een Nederlandsche kolonie te zijn, heen. Verder zijn er twee banden: de een heeft tot titel ,Antekening en Prothocol vervattende de Handelwijse zoo van het Eerwaarde Consistorium der Luthersche gemeente binnen Amsterdam als van derselver gecomitteerdens, D. us Wilhelm August Klepperbein, Predikant, en de Heer Anthony Bonn, ouderling, nopens het opregten van de Lutherse gemeente en hetgene verder int vervolg daaromtrent is voorgevallen in de colonie de Berbice, de Anno 1744 sqq"; de andere band bevat „de Copyen der Notulen, gehouden in de kerkelijke Vergaderingen onser gemeente in de colonie de Berbice, van tijd tot tijd aan ons overgesonden", en loopt van 1752 tot 1822; hierbij bevinden zich eenige losse stukken, op die gemeente betrekking hebbende. De voortzetting van de ",Antekening en Prothocol" vindt men in de zoogenaamde resolutieboeken van het consistorie, waarin tot 1824 nog gegevens omtrent de gemeente in Berbice te vinden zijn.

Suriname of Nederlandsch Guyana op de vaste kust van ZuidAmerika ligt tusschen Fransch Guyana ten Oosten en Engelsch Guyana ten Westen. Dit laatste bestond tot 1814, toen het aan Engeland werd afgestaan, uit drie Nederlandsche koloniën, Berbice, Demerary en Essequebo, zoo genoemd naar de drie rivieren, die van het binnenland naar de Atlantische oceaan stroomen. Men maakt zich van het geheel het best een voorstelling aan de hand van de kaart, die Netscher in 1887 samenstelde en aan zijn boek toevoegde; daar vindt men ook de ligging der plantages en sterkten aangegeven. Niet ver van de uitmonding van de Berbice vereenigt zich met deze de Canje-rivier.

In den tijd, waarin de geschiedenis der Luthersche kerk begint, was de kolonie Berbice in handen van een societeit op aandeelen, die een octrooi van de Staten-generaal had ontvangen en bestuurd werd door een directie in Nederland. In de kolonie was de gouverneur het hoogste gezag; hem stond ter zijde het Hof van politie, tevens uitoefenende de crimineele justitie, en een Raad van civiele justitie, beide colleges tellende zes leden met den gouverneur als voorzitter.

Fort Nassau op den rechter oever van de Midden-Berbice was de zetel van het bestuur ${ }^{1}$ ). Op de bovenverdieping van het fort

1) Plaat bij Hartsinck tegenover blz. 284 en 298. 
was de kerk der gereformeerde gemeente. Een andere gereformeerde kerk lag veel zuidelijker, daar, waar de Wironje-kreek de Berbice verlaat. Om het fort heen ontstond een dorp, NieuwAmsterdam geheeten. Daar was in 1734 een herberg gebouwd, 's-Lands welvaren, waar reizigers onderdak konden vinden en ook nieuwe kolonisten begonnen hun intrek te nemen; tevens was het koffiehuis.

Sedert omstreeks 1745 bevond zich aan den mond van de Canje-rivier een batterij of redoute, fort St-Andries genoemd naar den gouverneur Johan Andries Lössner (1740-1749) $\left.{ }^{1}\right)$. Nog vóór men, de Berbice opvarende, bij Fort Nassau kwam, had men op den linker oever de plantage der societeit Dageraad.

Lodewijk Abbensets is de man, die de stichter der Luthersche gemeente in Berbice moet genoemd worden. Hij riep in 1743 de Lutherschen in de kolonie bijeen en was, zoolang - en telkens wanneer - er geen predikanten waren, de voorzitter van de kerkeraads- en gemeentevergaderingen, tot zijn dood, in 1767, toe

Waarschijnlijk heeft hij zich in 1735, komende van Suriname, in Berbice gevestigd ${ }^{2}$ ). Daar had hij twee plantages: Mara tusschen de plantage Dageraad en den mond der rivier gelegen, en Solitude, westelijk van fort Nassau, verscheidene mijlen verder de rivier op, aan den linkeroever.

Abbensets is lid van het Hof van politie geweest. Voor dit lidmaatschap was in deze kolonie dus niet vereischt, dat men tot de gereformeerde kerk behoorde ${ }^{3}$ ).

Buiten zijn verdiensten voor de Luthersche gemeente in Berbice is over Abbensets verschillend geoordeeld. Dit staat in verband met zijn gedraging gedurende en vlak na den grooten slavenopstand in 1763. Toen die in Februari den gouverneur volkomen verraste, beval deze den kapitein Cock, die met zijn slavenschip

1) Plaat bij Hartsinck tegenover blz. 283.

2) De heer F. Oudschans Dentz te 's-Gravenhage vond in het journaal van den gouverneur van Suriname, dat op 14 Juli 1735 een pas verleend is aan Ludewig Abbensets. Volgens D e $\mathrm{N}$ e d e r la n ds c h e l e e u w, 1935, 214 was hij gehuwd met A. M. Coudrie, maar het blijkt niet, of deze zijn eerste of tweede vrouw was (zie hierna in den tekst).

3) Zooals in Curaçao, waar men tot de Luthersche kerk toetrad, om aan dezen lastpost, waarvoor men - ook in Berbice - niet bedanken mocht, te ontkomen, J. H. J. Hamelberg, De Nederlanders op de WestIndische eilanden I, 156, en het rapport van Grovestins en Boey in 1791 D e We s t-I ndis c h e Gid s I, 449. 
„Adriana Petronella" juist was aangekomen, de rivier op te varen tot de plantage Peereboom, bezuiden de Wironjekreek, om de daar door de rebellen ingesloten blanken te ontzetten. Cock heeft daaraan niet voldaan, maar is halverwege in de rivier blijven liggen. Abbensets was als lid van het Hof met een ander raadslid den kapitein Cock door den gouverneur nagezonden om diens bevelen te herhalen en een belooning uit te loven, maar verder dan tot Solitude, Abbensets' plantage, heeft Cock niet willen varen, en onder de blanken op Peereboom is een gruwelijke slachting aangericht. In de $\mathrm{Nederlandsche} \mathrm{ja} \mathrm{a} \mathrm{r} \mathrm{boeken} \mathrm{van}$ Augustus 1763 is de schuld van Cocks houding aan Abbensets geweten. Netscher ${ }^{1}$ ), die dit alles meedeelt, voegt daaraan toe, dat hem bij onderzoek gebleken is, dat Abbensets vrijuitgaat. Hij beroept zich daartoe op het oordeel van den gouverneur Van Hoogenheim ${ }^{2}$ ), die in een brief van 6 April 1763 aan de directie der kolonie Abbensets' gedrag in den eersten tijd van den opstand zeer geprezen heeft ${ }^{3}$ ).

Later was Van Hoogenheim echter minder over Abbensets te spreken, omdat deze, hoewel regeeringspersoon, behoorde tot de burgers, die op de schepen gevlucht waren. Het ergste maakte Abbensets het, nadat de opstand gedempt was. Als lid van den Raad van crimineele justitie zou hij partijdig zijn geweest: streng en wreed voor de slaven van anderen, buitengewoon toegevend voor zijn eigen slaven, die hij liefst vrijsprak om niet de schade te lijden, dat hij door doodvonnissen eenige van hen zou verliezen.

Als aanmatigend en heerschzuchtig wordt hij afgeschilderd. In April 1765 moest hij voor zijn eigen Raad terechtstaan, omdat hij een vrijen burger had afgeranseld. Hiervoor kreeg hij $f$ 250.boete, maar tevens sprak het Hof met eenparige stemmen uit, dat Abbensets' gedrag van dien aard was geweest, ,dat hij van deszelfs regterstoel en ampt als Raad zoowel van het College van 't Hof van Civiele Justitie als van dit College [het Hof van politie en crimin. just.] zal worden verklaart te zijn bedankt en niet meriteerd in eenen dier collegiën als lid te fungeeren".

Hiermee is vele jaren op de feiten vooruit geloopen. Ik meende

1) T.a.p. 197, 198, 397 e.v.

2) Wolfert Simon van Hoogenheim was van 1760 tot 1764 gouverneur der kolonie Berbice.

s) Ds. White deelt mee, dat Abbensets met een handvol menschen zich de slaven van het lijf hield. Hartsinck, 376 spreekt van een gerucht, dat Abbensets, die met eenige burgers en drie soldaten op Solitude post hield, genoodzaakt was de plantage te verlaten. De plantage zelf werd in asch gelegd; Hartsinck, 469. 
echter dit beeld, dat de geschiedenis schetst van den man, die nu herhaaldelijk zal worden genoemd in gunstiger licht, niet te moeten achterhouden.

In October 1743 wendden een zestigtal inwoners van Berbice, die ,d'onveranderde Augsburgsche confessie" verklaarden te zijn toegedaan, zich tot den gouverneur en zijn raden om voorspraak en medewerking, ten einde van de directie der kolonie te Amsterdam vrijheid van godsdienst te verkrijgen, het recht om een predikant te laten uitkomen en verder een kerk en school te stichten op eigen kosten, als hun geloofsgenooten in Suriname was toegestaan. Als reden voor hun verzoek voerden zij aan, dat zij, hoewel dankbaar voor de ,loffelijke en vredelievende Regeringe der overheyd" en de ,,vriendelijke samenleving met de belijders van de Christelijke Gereformeerde Religie", zonder vrijheid van godsdienstoefening altijd weer zouden verlangen naar de terugreis naar het vaderland, terwijl zij anders zich zeer gaarne in deze kolonie zouden vestigen.

Van de onderteekenaars mogen hier vijf worden genoemd, die met Abbensets als ,,gecommitteerde Bestierders" bij het consistorie der Luthersche gemeente te Amsterdam zijn opgetreden, nl. Jurriaan Hennings, P. M. Osterlin ${ }^{1}$ ), Jan Speelman, C. F. Götske en Joseph Dietz Scholt.

Gouverneur en raden hebben zich, naar monderling aan Abbensets is meegedeeld, 24 December 1743 over dit verzoek tot de directie in het moederland gewend. 11 Mei 1744 besloot deze laatste, dat aan de ingezetenen van de Augsburgsche confessie de openbare uitoefening van hun godsdienst zou worden toegestaan, waartoe een ,"bequaem, zeedigh en vreedelievend predikant", ,een gematigt man" aan directeuren ter goedkeuring zou moeten worden voorgedragen. Alleen dit gedeelte uit den desbetreffenden brief is bij wege van uittreksel ter kennis van de ,,gecommitteerdens" gebracht. Netscher deelt er nog uit mee, dat de directie in het moederland niet zonder zorg dit besluit nam, omdat de Lutherschen zoo weinig verdraagzaam waren.

28 October 1743 hadden de gecommitteerden aan het Amsterdamsche consistorie hun verzoekschrift, tot het bestuur in de kolonie gericht, meegedeeld. In den begeleidenden brief verklaarden zij het consistorie als moederkerk te erkennen en verzochten

1) Netscher, 178, noemt een landmeter en ingenieur Osterlin, die in 1712 met den gouverneur Waterham in de kolonie gekomen was; Hartsinck, 361 . 
zij het de gemeente te Berbice ,aan te neemen als een teedere jonge Dogter" en haar met „Moederlijke liefde, zorge en hulpe te assisteeren" door een verzoekschrift aan de directie der kolonie en zoo noodig ook aan de Staten-generaal te richten ter ondersteuning van hun verzoek. Zij deelden mee, dat voor éénduizend gulden ten behoeve van het predikantstraktement was ingeteekend, waarop echter geen staat kon worden gemaakt, omdat niet allen, die geteekend hadden, vaste ingezetenen der kolonie waren. Voor kerk en pastorie waren niet meer dan vijftienhonderd gulden bijeengebracht, en daarom werd voor dat doel een collecte in Amsterdam gevraagd. Een bekwaam voorlezer, voorzanger en schoolmeester zou wel in Berbice te vinden zijn. Met aandrang werd het consistorie verzocht ten spoedigste een ,bequaem en moderaat" predikant te beroepen en te doen uitgaan, en tevens te zenden een behoorlijk aantal Nederduitsche Bijbels, de nieuwe gezangboeken van Beudeker, catechismussen en hetgeen noodig is voor de /viering van het Heilig Avondmaal ,,als anders". Voor de jaarlijksche uitgaven werd voorloopig ook een beroep gedaan op de moederkerk.

Het antwoord van het consistorie, 23 Maart 1744 verzonden, moet voor de gemeente in Berbice wel zeer teleurstellend zijn geweest, omdat het een domper zette op haar stoute verwachting van hulp in het moederland te zullen vinden voor de vervulling van haar geestelijke behoeften. Het antwoord kwam hierop neer: hoe groot onze ijver ook is, wij moeten voorzichtig zijn, en met vasten grond onder de voeten beginnen, opdat de zaak ook bestendigd blijve. Vóór wij voor U vrijheid van godsdienstoefening vragen en een predikant beroepen, moet er een vast fonds zijn. Zoo is het in Suriname gegaan, en zoo hebben wij ook van Curaçao verlangd. En zelfs als moeder wenschte men deze dochter niet; dat kon wel eens geldelijke gevolgen hebben. „Onse gemeente alhier, als genoeg te doen hebbende met haar selve en met die van onse Nederlandse Provintie, waaronder veele behoeftige zijn, is niet in staat, vreemde gemeentens tot haar last, zelfs ten deele, aanteneemen".

De directie der kolonie was dus guller dan de kerk. Volgens May en White stelde het Hof van politie nog eenige voorwaarden bij het verleenen der vrijheid van godsdienstoefening. Zoo zouden de Lutherschen niet alleen al de kosten van hun kerk met wat daarbij behoort zelf moeten betalen, maar zij zouden ook moeten blijven doorbetalen voor de gereformeerde kerk. En in de tweede 
plaats zouden allen, die vrije kinderen van de kleur ten doop brachten, een verklaring moeten teekenen, dat deze kinderen nooit aanspraak zouden maken op een kerkelijke bediening of openbaar ambt. Is de eerste der zoo juist genoemde schrijvers van oordeel, dat deze bezwarende bepalingen haar oorzaak vonden in de vrees, dat de nieuwe kerk de slaven zou gaan onderwijzen en hen voor opstand rijp maken, de ander weet wel zeker, dat men hier alleen te doen heeft met een uiting van gereformeerde onverdraagzaamheid.

De kerkeraad te Berbice gaf den moed niet op. 8 Januari 1745 zond zij $f 2267.6$ over ter beschikking van het consistorie voor de uitzending van een predikant. Zij schreven verder, dat aan een fonds, waarvan de rente het onderhoud van den predikant zou kunnen bestrijden, in de jonge kolonie niet te denken viel, en het handhaven van dien eisch erop zou neerkomen ,ons voor altoos buyten staat te stellen ons heylsaam oogmerk en zugt tot de oefeninge onser heyligen Godsdienst te beryken". De brief van het consistorie had een averechtsche uitwerking gehad. Sommigen wilden nu niet bijdragen, vóór de medewerking van het consistorie was verkregen, of, nog liever, de predikant zou zijn aangekomen. Voor dat laatste geval waren er zelfs toezeggingen van gereformeerden, en van Lutherschen uit Essequebo.

Dat deze laatsten zeer begeerig waren naar een Luthersche godsdienstoefening blijkt uit een brief van 7 Juli 1746 van Joh. P. Schuler aldaar namens ,28 mans”, waarin de gouverneur Lössner verzocht werd tijdig mededeeling van den dag van den eersten Lutherschen kerkdienst in Berbice te doen, opdat zij daarvoor uit Essequebo zouden kunnen overkomen.

Voor het traktement en de vrije woning van den predikant kon men in Berbice instaan, en ten slotte wees men de heeren in Amsterdam erop, dat zij toch ook bijgedragen hadden voor het fonds in Suriname, en dat wellicht de gemeenten in Denemarken, Zweden, Hamburg, Lubeck en Dantzig mede tot collecteeren bereid zouden zijn. Het kerkeraadslid Götske zou naar Amsterdam gaan en met het consistorie de zaak komen bespreken.

Deze brief is voor het eerst medeonderteekend door het kerkeraadslid Carl Christ. Schirmeister, in Götske's plaats gekozen ${ }^{\mathbf{1}}$ ).

1) C. C. Schirmeister was, als Abbensets, lid van het Hof van politie, eigenaar van de plantages Oostermeer en Schermers genoegen. De gouverneur noemt de raadsleden Gillissen en Schirmeister , in de zaak van kapitein Cock even schuldig". Netscher, 197, 398. Hij overleed 20 October 1763. 
Het mocht niet baten: in een briefje van zeven regels werd 2 September 1745 in antwoord op het laatste schrijven uit Berbice eenvoudig verwezen naar hetgeen het consistorie het vorige jaar geschreven had.

Nog eenmaal, 23 Juli 1746, werd uit Berbice een dringend beroep op de Amsterdamsche gemeente gedaan, maar het slot van dezen brief komt hierop neer: wilt ge niet, stuurt ons dan ons geld terug, want dat moeten wij, als de zaak geen voortgang heeft, terugbetalen.

$\mathrm{Nu}$ vindt het consistorie er iets op: ds. Klepperbein ${ }^{1}$ ) zal ,en privé, dog met communicatie van het E. consistorium" trachten in Duitschland een rechtzinnigen predikant voor Berbice te vinden; er is dan geen officieele band tusschen de Amsterdamsche gemeente en die in de West, welke geldelijke verantwoordelijkheid en aansprakelijkheid kan meebrengen, maar men helpt de nieuwe gemeente en blijft op de hoogte.

In Berbice was men (brief van 16 Mei 1747) overgelukkig met deze oplossing; men wilde zich nu voor den tijd van zes jaren verbinden om jaarlijks een traktement van $f$ 1000.- te betalen. Deze brief was als steeds aan het consistorie gericht, dat daarop nog eens vastlegde: wij kunnen den te beroepen predikant geen consistorialen beroepsbrief geven, ,,veel minder UEerw. gemeente als eene Filial-kerke van de onse.... erkennen en aan.... nemen" (11 September 1747). Misschien later dan, antwoordden de „,bestierders" te Berbice; wij zullen de zaken nu dus verder met ds. Klepperbein afdoen (brief van 7 Maart 1748; bij de onderteekenaars zijn nieuw de namen van Jan Reijnhout Reijmers en Carl Wentzel Krzidlowsky).

(wordt vervolgd).

1) Wilhelm August Klepperbein, sinds 1738 predikant te Amsterdam; daarvóór was hij eerst vier jaren predikant te Westrum en eenige maanden te Oldorp in Jeverland. 1779 werd hij te Amsterdam emeritus, $\dagger$ 1786. Zie, F. J. Domela Nieuwenhuis, Geschiedenis der Amsterdamsche Luthersche gemeente, 151. 